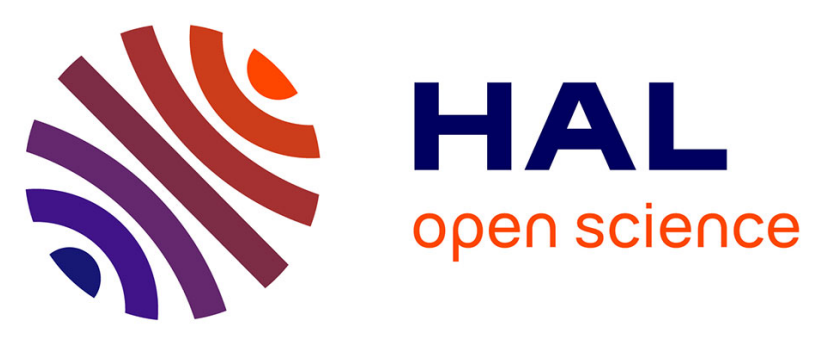

\title{
The Legionella pneumophila Methyltransferase RomA Methylates Also Non-histone Proteins during Infection
}

Maren Kirstin Schuhmacher, Monica Rolando, Alexander Bröhm, Sara Weirich, Srikanth Kudithipudi, Carmen Buchrieser, Albert Jeltsch

\section{- To cite this version:}

Maren Kirstin Schuhmacher, Monica Rolando, Alexander Bröhm, Sara Weirich, Srikanth Kudithipudi, et al.. The Legionella pneumophila Methyltransferase RomA Methylates Also Nonhistone Proteins during Infection. Journal of Molecular Biology, 2018, 430 (13), pp.1912-1925. 10.1016/j.jmb.2018.04.032 . pasteur-02869016

\section{HAL Id: pasteur-02869016}

https://hal-pasteur.archives-ouvertes.fr/pasteur-02869016

Submitted on 15 Jun 2020

HAL is a multi-disciplinary open access archive for the deposit and dissemination of scientific research documents, whether they are published or not. The documents may come from teaching and research institutions in France or abroad, or from public or private research centers.
L'archive ouverte pluridisciplinaire HAL, est destinée au dépôt et à la diffusion de documents scientifiques de niveau recherche, publiés ou non, émanant des établissements d'enseignement et de recherche français ou étrangers, des laboratoires publics ou privés.

\section{(1) (1) $\$$}

Distributed under a Creative Commons Attribution - NonCommercial - NoDerivatives 44.0 


\section{The Legionella pneumophila methyltransferase RomA methylates also non-histone proteins during infection}

Maren Kirstin Schuhmacher ${ }^{1}$, Monica Rolando ${ }^{2,3}$, Alexander Bröhm ${ }^{1}$, Sara Weirich ${ }^{1}$, Srikanth Kudithipudi ${ }^{1}$, Carmen Buchrieser ${ }^{2,3}$ \& Albert Jeltsch ${ }^{1, *}$

${ }^{1}$ Department of Biochemistry, Institute of Biochemistry and Technical Biochemistry, University Stuttgart, Allmandring 31, 70569 Stuttgart, Germany 2Institut Pasteur, Biologie des Bactéries Intracellulaires, 75724 Paris, France ${ }^{3}$ CNRS UMR 3525, 75724 Paris, France

${ }^{*}$ Corresponding author:

Phone: +4971168564390

Fax: +4971168564392

E-mail: albert.jeltsch@ibtb.uni-stuttgart.de

http://www.ibtb.uni-stuttgart.de/bc

\section{Subject area}

Structure, chemistry, processing and function of biologically important macromolecules and complexes 


\section{Abstract}

RomA is a SET-domain containing protein lysine methyltransferase encoded by the Gram-negative bacterium Legionella pneumophila. It is exported into human host cells during infection and has been previously shown to methylate histone $\mathrm{H} 3$ at lysine 14 (Rolando et al., 2013, Cell Host Microbe 13:395-405). Here, we investigated the substrate specificity of RomA on peptide arrays showing that it mainly recognizes a G$\mathrm{K}-\mathrm{X}-(\mathrm{PA})$ sequence embedded in a basic amino acid sequence context. Based on the specificity profile, we searched for possible additional RomA substrates in the human proteome and identified 34 novel peptide substrates. For nine of these, the corresponding full length protein or protein domains could be cloned and purified. Using radioactive and antibody based methylation assays, we showed that seven of them are methylated by RomA, four of them strongly, one moderately, and two weakly. Mutagenesis confirmed for the seven methylated proteins that methylation occurs at target lysine residues fitting to the specificity profile. Methylation of one novel substrate (AROS) was investigated in HEK293 cells overexpressing RomA and during infection with Legionella pneumophila. Methylation could be detected in both conditions, confirming that RomA methylates non-histone proteins in human cells. Our data show that the bacterial methyltransferase RomA methylates also human non-histone proteins suggesting a multifaceted role in the infection process. 


\section{Graphical abstract}
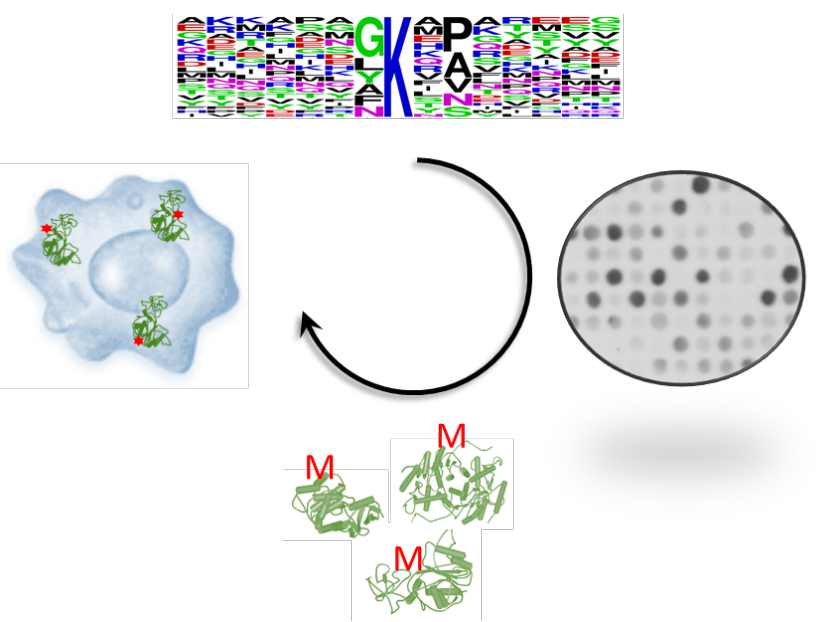

\section{Highlights}

- RomA recognizes a G-K-X-(PA) sequence

- RomA methylates 34 novel non-histone peptide substrates

- Methylation on 7 out of 9 tested substrates was observed at the protein level

- RomA methylates AROS in human cells during infection

- These data suggest that RomA has a multifaceted role in pathogenicity

\section{Key words}

Enzyme specificity; Legionella pneumophila; Non-histone substrate; Protein methylation; Protein lysine methyltransferase 


\section{Introduction}

Legionella pneumophila is a Gram-negative bacterium that infects freshwater protozoa and replicates within them. Several different species of amoebae and ciliated protozoa have been shown to be potential environmental hosts for legionellae. When L. pneumophila contaminated water droplets are inhaled by humans, the bacterium can infect the alveolar macrophages in the lung and cause a severe form of pneumonia called Legionnaire's disease. ${ }^{1}$ The ability of $L$. pneumophila to infect and persist in protozoan and human host cells relies on a highly specialized Type-4 secretion system (T4SS) known as Dot/lcm secretion system. 2; 3;4 Uniquely, L. pneumophila employs its T4SS to translocate more than 300 effectors into the host cell that are essential to establish a replication vacuole, in which the bacterium can proliferate by hijacking the host cell response to infection. ${ }^{5}$ Genome analyses revealed that many of the secreted effectors have eukaryotic-like properties, thus illustrating the close co-evolution between L. pneumophila and its protozoan hosts. ${ }^{6}$ Several of these effectors have already been shown to interfere with organelle biogenesis and to counteract host cell responses. ${ }^{7}$ Importantly, recently it has been shown that L. pneumophila targets the human host cell nucleus to modify the transcriptional response to the pathogens advantage. $^{8}$

The nucleus of eukaryotic cells has a complex organization where nuclear chromatin is organized in a highly ordered and dynamic structure that ensures the regulation of DNA accessibility for transcription, DNA repair and replication. The chromatin structure is tightly regulated by post-translational modifications (PTMs) including DNA methylation or histone modifications, such as acetylation, phosphorylation, ubiquitination, sumoylation or methylation. ${ }^{9}$ 10; 11 These so-called epigenetic modifications are dynamically regulated by specialized enzymes and induce changes in gene expression without modifying the DNA sequence. Recently, it has been shown that pathogens such as Listeria monocytogenes, Chlamydia trachomatis, Bacillus anthracis or Shigella flexneri may impose specific transcriptional profiles on the host cell via bacteria induced chromatin remodeling. ${ }^{12}$ L. pneumophila is a member of this group of pathogens as this bacterium modifies chromatin by directly depositing PTMs on histone proteins. One chromatin modifying factor in L. pneumophila (secreted via its T4SS) is RomA for which we previously showed it methylates lysine 14 of histone H3 (H3K14). ${ }^{13}$ This specific modification leads to a switch from H3K14 acetylation to 
methylation and subsequently to downregulation of gene expression, which supports the efficient intracellular replication of the bacterium. ${ }^{13}$ LegAS4 is the homologous lysine methyltransferase of L. pneumophila strain Philadelphia, which encodes a SET domain identical to that of RomA and an ANK domain that is $95 \%$ identical. The structure of LegAS4 has been solved in complex with AdoMet. ${ }^{14}$ This structure shows that the protein consists of an N-terminal domain (residues 1-60), the SET domain (84253) and an ankyrin repeat-containing domain (267-532). It had been reported that LegAS4 methylates histone $\mathrm{H} 3$ at lysine 4 and $9,,^{15}$ but the relevance of this finding is unclear, because it was shown that LegAS4 strongly methylates K14 of histone H3 like RomA. ${ }^{16}$.

Although RomA showed a strong methylation activity on lysine 14 of histone H3, the question whether this bacterial PKMT might also target additional non-histone proteins remained open. In fact, lysine methylation of non-histone proteins is a frequent modification in eukaryotic cells and many PKMTs were identified to methylate nonhistone targets in addition to histone substrates. ${ }^{17}$;8; 19 To identify novel PKMT substrates, we have developed a method which has been successfully applied for several different human PKMTs. ${ }^{20 ; 21 ; 22 ; 23}$ In this approach, we first determine the substrate specificity profile of the PKMT, and then based on this profile we predict and validate novel substrates in the human proteome. In this study, we used peptide arrays to determine the substrate specificity profile of RomA and to discover novel human, non-histone RomA substrates. We identified several novel substrates that were methylated at peptide and protein level and confirmed methylation of one of these proteins in human cells during L. pneumophila infection. Based on these findings RomA is the first bacterial PKMT that methylates a human non-histone protein during infection.

\section{Results}

Enzyme activity testing revealed specific H3K14 peptide recognition of RomA The methyltransferase RomA (Ipp1683) from L. pneumophila (strain Paris) was cloned into the pGEX-4T2 bacterial expression vector. ${ }^{13}$ The protein was overexpressed in $E$. coli cells and purified using glutathione sepharose beads. The purified protein was analyzed by SDS-PAGE and Coomassie BB staining showing a good yield and purity (Fig. 1A). To investigate the catalytic activity of RomA, methylation reactions were 
performed using recombinant $\mathrm{H} 3$ protein as substrate and radioactively labeled [methyl- ${ }^{3} \mathrm{H}$ ]-S-adenosyl-L-methionine (AdoMet) as cofactor (Fig. 1A). The methylation sample was separated using SDS-PAGE and the methylation signal was visualized by autoradiography. The obtained autoradiography film showed a clear methylation signal at the size of the recombinant $\mathrm{H} 3$, which confirms the expected activity of the purified RomA enzyme under the used conditions. We then performed a target lysine scan using peptide SPOT arrays with fifteen amino acid long peptides (Fig. 1B). Interestingly, only one peptide spot (spot 5) showed a strong methylation signal, which contains the $\mathrm{H} 3$ peptide with centered $\mathrm{K} 14$. A very weak K4 methylation signal was detected as well (compare spots 1 and 2), but quantification showed that it is below 5 $\%$ of the activity at $\mathrm{K} 14$ and very close to background fluctuations. It probably reflects some unspecific activity of RomA. The strong H3K14 methylation indicates that H3K14 is the main methylation target of RomA in agreement with our previous studies. ${ }^{13 ; 16}$

\section{Substrate specificity profiling of RomA identified its substrate recognition motif} After confirming the activity and primary specificity of RomA, we investigated its substrate specificity in detail using substrate specificity scan peptide arrays based on the H3 (7-21) peptide sequence as template. In the substrate specificity profile array single mutant peptides were prepared in which each amino acid of the H3 (7-21) sequence was exchanged against all proteinogenic amino acids (only excluding tryptophan and cysteine, because of their unfavorable coupling properties). For methylation, the peptide array was incubated with RomA in the presence of radioactively labeled AdoMet. This step was followed by the detection of the transferred radioactively labeled methyl groups to the peptides by autoradiography (Fig. 2A). The relative methylation of the single mutant peptides provides a detailed view on the recognition of each amino acid in the target sequence by the PKMT under investigation. $^{24}$ The peptide array methylation experiments were conducted in duplicates and the two individual results were normalized and averaged (Fig. 2B). Most of the methylation activities showed a standard deviation (SD) smaller than $10 \%$ indicating high reproducibility (Fig. 2C). As a next step, discrimination factors were calculated as previously described. ${ }^{24}$ These factors illustrate and quantitatively describe the preference of RomA in the acceptance and preference of the different amino acids at each position of the $\mathrm{H} 3$ (7-21) sequence (Fig. 2D). For additional 
visualization, a sequence logo of the specificity profile of RomA (Fig. 2E) was prepared using Weblogo (http://weblogo.berkeley.edu/). ${ }^{25}$

The substrate specificity profile of RomA indicated that the enzyme is highly specific in the recognition of the -1 position (when K14 is annotated as 0 ), because at this site only glycine is accepted by the enzyme indicating that a GK motif (amino acid G13 and $\mathrm{K} 14$ in H3) represents the most important recognition element of RomA. The second specific site is the +2 position, where only the natural proline and to a lesser extent alanine are accepted. At the -2 position, where $G$ is the natural amino acid, $A, N, G, K$, $\mathrm{M}, \mathrm{S}$ or $\mathrm{V}$ are preferred amino acid residues. At the +3 position $\mathrm{A}$ and $\mathrm{K}$, are preferred, besides the natural amino acid R. V, Q, G and $S$ are tolerated at this site as well. The +1 position is not specifically recognized. Altogether RomA has a recognition motif ranging from the -2 to +3 position of the target sequence, which can be summarized as follows (the natural residues at each position are indicated in bold):

$($ ANGKMVS) $-\mathbf{G}-\underline{\mathbf{K}}-($ not $\mathrm{D}, \mathrm{G}, \mathrm{P})-(\mathrm{P}>\mathrm{A})-(\mathrm{ARK}>\mathrm{VSQG})$

RomA methylates 34 non-histone peptide substrates in vitro

To investigate whether RomA methylates human non-histone proteins in addition to H3K14, we performed a Scansite search (http://scansite.mit.edu) ${ }^{26}$ in the human proteome based on a reduced version of the above mentioned substrate specificity profile of RomA: (ANGKMV) - G - $\underline{K}-\mathrm{X}-\mathrm{P}-$ (ARKVS) (X denotes for any amino acid). The reduced profile was used in order to focus the search on the most promising human non-histone targets of RomA. As a result, we retrieved 93 potential non-histone targets. We prepared SPOT arrays comprising fifteen amino acid long peptides with the putative target lysine residue of the potential non-histone substrates in the center. The already known substrate H3K14 (7-21) was included as positive control. As a negative control for all peptides, a lysine to alanine mutant (for example H3K14A) was included, which allowed to confirm that the methylation indeed occurs at the target lysine residue. The peptide array was incubated with RomA in the presence of radioactively labeled AdoMet and the signal was detected by autoradiography (Fig. $3 A)$. We observed that 34 of the 93 peptides were methylated with similar activity as H3K14 or a little weaker (Table 1). Loss of methylation of the $K$ to $A$ mutant peptide confirmed methylation at the predicated target site. About 15 more peptides showed 
weaker methylation, but still loss of methylation of the mutant peptides. These substrates were not further investigated. We compared the peptide sequences of the methylated and non-methylated peptides and observed that methylated peptides are enriched in positively charged residues (Fig. 3B), which is in agreement with the LegAS4 structure showing conserved surface glutamate residues, which were implicated in substrate protein interaction. ${ }^{14}$ Overall, these findings illustrate that the specificity profile method is very successful in the prediction of novel RomA substrates.

Seven non-histone protein substrates are methylated by RomA in vitro

We then aimed to analyze if 30 of these peptide targets were methylated at the protein level as well. We tried to clone these substrates into the pGEX-6p2 bacterial expression vector as full length or domain proteins containing the target lysine residue and purify them after expression in E. coli. Many substrates failed at either the cloning, overexpression, or purification step but nine proteins could be successfully purified (Table 2). Comparable amounts of these proteins were incubated with RomA and recombinant $\mathrm{H} 3$ protein $(\mathrm{H} 3 \mathrm{~K} 14)$ as positive control in the presence of radioactively labeled AdoMet. After the methylation reaction, the samples were separated by SDSPAGE and the transfer of radioactive methyl groups to the substrate proteins was detected by autoradiography. Our data show that indeed seven substrates were methylated by RomA, four of them strongly, one moderately, and two weakly (Fig. 4), while two of them showed no methylation signal (Suppl. Fig. 1). The Kinesin-like protein KIFC1 (KIFC1), Forkhead box protein O4 (FOXO4), Retinoic acid induced protein 1 (RAI1) and Active regulator of SIRT1 (AROS) showed strong methylation, moderate methylation was detected for Mediator of RNA polymerase II subunit 13 (MED13) while Protein CBFA2T2 (CBFA2T2), and HMG box transcription factor BBX (BBX) showed weak methylation.

To confirm that KIFC1, AROS, MED13, RAI1, BBX and CBFA2T2 are indeed methylated at the predicted target $\mathrm{K}$ residue, we constructed $\mathrm{K}$ to $\mathrm{R}$ mutants of each of the proteins. Cloning and overexpression of the six mutant proteins was successful and all proteins could be purified in comparable quality and amounts as the corresponding wild type proteins (Fig. 5). Methylation analysis was conducted as described above, strikingly revealing a complete loss of the methylation signal of all mutant proteins. In the case of $\mathrm{FOXO} 4$, we identified four potential partial matches of 
lysine residues to the RomA preferences within its amino acid sequence (Fig. 6A). We generated several mutant proteins and tested their methylation (Fig. 6B) allowing us to identify that the methylation occurred at three sites K210 > K189 > K186 (Fig. 6C). This result highlights the important role of the positive charge of the target region (Fig. $3 \mathrm{~B}$ ), because the two most strongly methylated $\mathrm{K}$ residues are embedded in a basic amino acid sequence context. Altogether, we identified seven non-histone substrates of RomA at protein level in vitro and confirmed their methylation at target $\mathrm{K}$ residues fitting to the sequence preferences of RomA.

\section{Confirmation of the methylation of non-histone targets by Western Blot}

In addition to the detection of non-histone substrate methylation by RomA with radioactively labeled AdoMet, we verified the protein methylation by Western Blot using two different anti-pan di/trimethyl-lysine antibodies. Previously, we have shown that RomA introduces di- and trimethylation on H3K14 using MS/MS. ${ }^{13}$ The antibody analysis was performed after the methylation of the non-histone protein substrates by RomA in the presence of unlabeled AdoMet. For each non-histone target, a corresponding unmethylated sample was prepared as negative control in which RomA was not added to the reaction. After the methylation reactions, the substrate proteins were separated by SDS-PAGE, transferred onto nitrocellulose membranes and analyzed by Western Blot using the anti-pan di/trimethyl-lysine antibodies. For the FOXO4, AROS, KIFC1, and recombinant $\mathrm{H} 3$, a strong Western Blot signal was observed in the methylated samples, while no signal was observed with the unmethylated sample (Fig. 7). This confirms the methylation of these proteins by RomA in vitro. With BBX, no antibody signal was detected (data not shown), which is in agreement with the results of the methylation with radioactively labeled AdoMet, in which BBX was only very weakly methylated. For RAl1 a similar weak signal was observed for the unmethylated and methylated samples indicating that the antibody cannot be used to detect RAl1 methylation (data not shown). In conclusion, the antipan di/trimethyl-lysine antibodies confirmed the methylation of three human nonhistone targets (KIFC1, FOXO4, AROS) by RomA.

AROS is methylated by RomA in vivo during infection of human cells

As described above, we demonstrated that $L$. pneumophila RomA methylates human non-histone protein substrates. To test whether methylation of the identified non- 
histone proteins is taking place also in vivo during infection, we selected the AROS protein, because it was among the strongly methylated proteins and AROS has been described as a regulator of the human histone deacetylase SIRT1. ${ }^{27}$ However, methylation of AROS on K54 has never been reported. We first tested the methylation of AROS in cell lines stably expressing RomA or its catalytically inactive form (Y249F/R207G/N210A). ${ }^{13}$ Figure 8A shows that after immunoprecipitation of AROS proteins the methylated form of AROS was detected with an anti-pan di/trimethyl-lysine antibody when RomA was expressed, but AROS was not methylated in cells that expressed the catalytically inactive enzyme $(\mathrm{Cl})$. Thus, RomA methylates AROS in human cells.

Next, we infected HEK293T cells for eight hours with both wild type L. pneumophila and the L. pneumophila $\Delta / p p 1683$ mutant strain, where the gene coding for RomA is deleted, to analyze whether methylation of AROS is taking place during infection. We collected protein lysates and performed immunoprecipitation experiments to enrich the AROS protein and subsequently blotted with anti-pan di/trimethyl-lysine antibody (Fig. 8B). Indeed, methylation of AROS was observed in cells infected with wild type L. pneumophila expressing the RomA enzyme, but not in uninfected cells and cells infected with the RomA deleted strain. This finding was supported by the colocalization of co-transfected AROS and RomA in the nucleus of Hela cells (Fig. 8 CE). We conclude that RomA methylates AROS, a non-histone target, during infection of human cells.

\section{Discussion}

Recent discoveries proved that lysine methylation is not histone specific and showed that histone methylating enzymes like G9a, ${ }^{20} \mathrm{SET7} / 9,{ }^{21} \mathrm{SUV} 39 \mathrm{H} 1,{ }^{23}$ or NSD1 ${ }^{22}$ can also methylate other substrates in addition to those originally discovered. Thus searching for additional substrates of PKMTs is an emerging field of research. ${ }^{17 ;} 19 ; 28$ Lysine methylation may regulate protein function by providing specific docking sites for interacting proteins. ${ }^{29}$ Furthermore, methylation can serve to inhibit alternate PTMs on the same lysine residue, like we observed for RomA and the H3K14 residue, where methylation prevents acetylation. ${ }^{13}$ In addition, the combinatorial activity of mono-, dior trimethylation provides enormous functional diversity and regulatory complexity. Thus, the methylation of non-histone substrates by PKMTs can have different 
outcomes, for example affecting protein stability, conformations or regulation of interactions with other proteins. ${ }^{28}$

We identified a (ANGKMV) $-\mathrm{G}-\underline{\mathrm{K}}-\mathrm{X}-\mathrm{P}-(\mathrm{ARKVS})$ motif embedded in a basic amino acid sequence context which characterizes strong methylation sites of RomA, but show that weaker activity is also observed at other sites. Based on this motif, we discovered 34 new human non-histone peptide substrates of the L. pneumophila methyltransferase RomA. We successfully purified nine of the candidate substrate protein or protein domains and confirmed protein methylation for seven of them. This result suggests that many of the other validated peptide substrates, for which methylation could not be analyzed at the protein level due to technical problems, are likely to be methylated by RomA at protein level as well. Using mutant proteins where the target lysine was mutated to arginine and in vitro protein methylation of the seven confirmed proteins, we showed experimentally that these proteins are indeed methylated at the target lysine residues fitting to the specificity profile of RomA. To confirm the biological relevance of those modifications, it was essential to verify their methylation in human cells infected by L. pneumophila. We tested lysine methylation of AROS both in RomA expressing HEK293 cells as well as in infected cells and observed clear RomA dependent methylation signals, suggesting that many of the other protein substrates can be methylated in cells as well.

FOXO4, a member of the mammalian Forkhead box $\mathrm{O}$ transcription factors, is acetylated on K186 and K189 by the CREB-binding protein, a known histone acetyltransferase that acts as a co-activator of numerous transcription factors ${ }^{30}$ and it is deacetylated by SIRT1. ${ }^{31}$ Thus, given the inhibitory role of lysine methylation on acetylation of the same residue, a similar mechanism may operate for RomA methylation of FOXO4 like for $\mathrm{H} 3$ at K14. However, we did not find a good antibody against FOXO4 that would have allowed us to perform immunoprecipitation and to study its methylation in vivo. AROS is a small protein also termed RPS19BP1 for RSP19 (40S ribosomal protein S19) Binding Protein 1, that is able to shuttle between the nucleus, where it co-localizes with RomA and supports ribosome biogenesis, and the cytoplasm, where it interacts with the translation machinery and plays a role in maintaining the maximal rate of global protein synthesis. ${ }^{32}$ AROS has also been identified as a direct interactor of the deacetylase SIRT1, promoting SIRT1-mediated 
suppression of $\mathrm{p} 53 .{ }^{27}$ However, a direct regulation of AROS by methylation has never been observed and a possible role of its methylation in regulating SIRT1 deacetylase activity remains an open question.

\section{Conclusions}

Taken together, we identified seven non-histone targets of RomA of which AROS was shown to be also a RomA target during infection in human cells. In extrapolation our data suggest that many more of the identified peptide substrates are also methylated at protein level in vitro and in cells. Future studies will investigate the role of AROS methylation induced by RomA, and whether the methylation of some of these human proteins has an equally important function as the histone H3K14 methylation reported previously. ${ }^{13}$ Moreover, it will be interesting to investigate the potential methylation of protozoan proteins by RomA and its role in the replication and persistence of L. pneumophila in the environmental hosts as well.

\section{Material and Methods}

Cloning, Expression and purification of the proteins

The expression construct of the full length GST tagged RomA gene Ipp1683 (GenBank entry CAH12835) was cloned into pGEX-4T2. ${ }^{13}$ The domains or full-length non-histone substrates were cloned by PCR using cDNA isolated from HEK293 cells into the pGEX-6p2 expression vector for bacterial expression. Protein domains were predicted using Scooby domain prediction (http://www.ibi.vu.nl/programs/scoobywww/). ${ }^{33}$ The lysine to arginine mutants were introduced by site directed mutagenesis ${ }^{34}$ and confirmed by sequencing. Thereafter, the bacterial expression constructs were transformed into BL21 DE3 Codon Plus cells for protein expression. The overexpression of the non-histone proteins was performed in Luria-Bertani medium, which was supplemented with ampicillin. The main expression culture was grown at $37^{\circ} \mathrm{C}$ till an $\mathrm{OD}_{600}$ between 0.6 and 0.8 was reached. Afterwards, it was transferred to $20^{\circ} \mathrm{C}$ and the protein expression was induced overnight by the addition of $1 \mathrm{mM}$ isopropyl-B-D-thiogalactopyranoside (IPTG). Then, the cells were harvested by centrifugation at $4000 \mathrm{~g}$ for 20 minutes at $4^{\circ} \mathrm{C}$. The cell pellet was resuspended in $1 \mathrm{x}$ STE buffer (100 mM NaCl, $10 \mathrm{mM}$ Tris/HCl pH 8, $0.1 \mathrm{mM}$ EDTA) and centrifuged again at $4500 \mathrm{~g}$ for 20 minutes at $4^{\circ} \mathrm{C}$. The obtained pellet was stored at $-20^{\circ} \mathrm{C}$. 
For the purification of the proteins, the pellets were thawed and resuspended in $25 \mathrm{ml}$ sonication buffer (50 mM Tris/ $\mathrm{HCl} \mathrm{pH} \mathrm{7.5,} 150 \mathrm{mM} \mathrm{NaCl}, 1 \mathrm{mM}$ DTT, 5 \% glycerol) and sonicated to release the proteins from the cells (Bandelin Sonopuls HD2200 and UW2200: 30\% power, 12x 15 seconds, 4 cycles). Afterwards, the cell lysate was centrifuged at $18000 \mathrm{~g}$ for 90 minutes at $4^{\circ} \mathrm{C}$. The obtained supernatant was loaded onto glutathione sepharose 4B beads equilibrated with sonication buffer. The column was washed once with sonication buffer and twice with wash buffer $(50 \mathrm{mM}$ Tris/ $\mathrm{HCl}$ $\mathrm{pH} 8,500 \mathrm{mM} \mathrm{NaCl}, 1 \mathrm{mM}$ DTT, $5 \%$ glycerol). The washing steps were followed by the fractionated elution of the protein using wash buffer supplemented with $40 \mathrm{mM}$ reduced glutathione. The pooled protein fractions were dialyzed in dialysis buffer I (20 $\mathrm{mM}$ Tris/ $\mathrm{HCl} \mathrm{pH} 7.4,100 \mathrm{mM} \mathrm{KCl}, 0.5 \mathrm{mM}$ DTT, $10 \%$ glycerol) for 3 hours, followed by overnight dialysis in dialysis buffer II $(20 \mathrm{mM}$ Tris/ $\mathrm{HCl} \mathrm{pH} \mathrm{7.4,100} \mathrm{mM} \mathrm{KCl,} 0.5 \mathrm{mM}$ DTT, $60 \%$ glycerol) and stored at $-20^{\circ} \mathrm{C}$. After purification, the obtained proteins were analyzed by SDS-PAGE using an unstained molecular weight marker (ThermoFisher Scientific, cat. no. 26610) for size determination.

\section{Peptide array methylation}

For the preparation of the peptide arrays the SPOT synthesis method and an Autospot peptide array synthesizer (Intavis AG, Köln, Germany) were used. ${ }^{24 ;} 35$ The arrays contained fifteen amino acid long peptides spotted on a cellulose membrane. The membrane was pre-incubated in methylation buffer $(50 \mathrm{mM}$ Tris/ $\mathrm{HCl} \mathrm{pH}$ 9, $2.5 \mathrm{mM}$ $\mathrm{MgCl}_{2}, 4 \mathrm{mM}$ DTT) for 5 minutes and then incubated in methylation buffer supplemented with $0.76 \mu \mathrm{M}$ radioactively labeled AdoMet (Perkin Elmer) and different concentations of RomA (7.5-60 nM) for 60 minutes. This step was followed by 5 times washing for 5 minutes with wash buffer (100 $\mathrm{mM} \mathrm{NaHCO}_{3}, 1 \% \mathrm{SDS}$ ) and incubation for 5 minutes in amplify NAMP100V (GE Healthcare). Then, the membrane was exposed to a Hyperfilm ${ }^{\text {TM }}$ high performance autoradiography film (GE Healthcare) at $80^{\circ} \mathrm{C}$ in the dark for different periods of time. The film was developed using an Optimax Typ TR machine.

\section{Protein methylation assay}

The methylation of non-histone substrate proteins and recombinant H3.1 (NEB) was performed in methylation buffer (50 mM Tris/ $\mathrm{HCl} \mathrm{pH} 9,2.5 \mathrm{mM} \mathrm{MgCl}, 4 \mathrm{mM}$ DTT) containing $0.76 \mu \mathrm{M}$ radioactively labeled AdoMet and $0.9 \mu \mathrm{M}$ RomA enzyme. The 
reaction was performed for 3 hours at $25^{\circ} \mathrm{C}$ and then halted by the addition of SDS loading buffer and incubation of the samples for 5 minutes at $95^{\circ} \mathrm{C}$. Afterwards, the samples were loaded and separated by $16 \%$ SDS-PAGE using a pre-stained molecular weight marker (ThermoFisher Scientific, cat. no. 26616) for size determination. The SDS-gel was incubated for 45 minutes in amplify NAMP100V (GE Healthcare) and dried for 90 minutes at $60^{\circ} \mathrm{C}$ in vacuum. Then, the dried SDS-gel was exposed to a Hyperfilm ${ }^{\mathrm{TM}}$ high performance autoradiography film (GE Healthcare) at $80^{\circ} \mathrm{C}$ in the dark for different periods of time. The exposed film was developed using an Optimax Typ TR machine.

\section{Western Blot protein methylation assay}

The methylation was performed as described above except that unlabeled AdoMet (Sigma Aldrich) was used in a concentration of $1 \mathrm{mM}$. After separation of the samples on a $16 \%$ SDS-PAGE, the samples were transferred onto a nitrocellulose membrane by a Trans-Blot $®$ Turbo ${ }^{\mathrm{TM}}$ system (Bio-Rad). After transfer, the membrane was stained with PonceauS and an image was captured. The nitrocellulose membrane was then blocked overnight in $5 \%$ milk-PBST solution at $4^{\circ} \mathrm{C}$. The membrane was washed three times for 5 minutes with 1x PBST (140 mM NaCl, $2.7 \mathrm{mM} \mathrm{KCl}, 4.3 \mathrm{mM} \mathrm{Na}_{2} \mathrm{HPO}_{4}, 1.4$ $\mathrm{mM} \mathrm{KH}_{2} \mathrm{PO}_{4}, 0.05 \%$ Tween 20) and afterwards incubated with the primary antibody anti-pan di/trimethyl-lysine (1:1000, Upstate, cat. no. 07-756 or 1:5000, Abcam, cat. no. ab23367) for 60 minutes. Thereafter, the membrane was washed as described above. The Abcam anti-pan di/trimethyl-lysine antibody was linked with horseradish peroxidase. In the case of the Upstate anti-pan di/trimethyl-lysine antibody, the membrane was incubated with the secondary antibody anti-rabbit linked with horseradish peroxidase (1:5000, GE Healthcare, cat. no. NA934V) for 60 minutes. After washing, the membrane was developed using an enhanced chemiluminescence ECL solution (Perkin Elmer). The signal was detected using a Hyperfilm ${ }^{\mathrm{TM}}$ high performance autoradiography film (GE Healthcare) and an Optimax Typ TR developing machine. For in vivo studies the Abcam antibody was used, because the Upstate antibody was no longer available.

Bacterial strains, growth media and culture conditions

Legionella pneumophila strain Paris and its derivatives were cultured in $\mathrm{N}$-(2acetamido)-2-aminoethanesulfonic acid (ACES)-buffered yeast extract broth or on 
ACES-buffered charcoal-yeast (BCYE) extract agar. ${ }^{36}$ The RomA mutant ( $\triangle$ /pp1683) was constructed as previously described. ${ }^{13}$

\section{Immunoprecipitation and Immunoblot}

Immunoprecipitation was performed in HEK293T cells, infected for 8 hours with both L. pneumophila wild type or a RomA deletion mutant $(\Delta / p p 1683)$ at an $\mathrm{MOI}$ of 100 . Cells were grown in DMEM (Invitrogen) supplemented with $10 \%$ of fetal bovine serum (Biowest) and seeded at a density of $8^{*} 10^{6}$ cells into $100 \mathrm{~mm}$ culture dishes (TPP) 24 hours before infection. Eight hours after infection, the cells were washed with prechilled PBS at $4^{\circ} \mathrm{C}$ and incubated with $500 \mathrm{ml}$ of lysis buffer $(1 \%$ Triton, $20 \mathrm{mM}$ Tris/ $\mathrm{HCl}$ $\mathrm{pH}$ 7.4, $150 \mathrm{mM} \mathrm{NaCl}, 1 \mathrm{mM}$ EDTA, $1 \mathrm{mM}$ EGTA and protease inhibitor cocktail, Roche). Cells were scraped and collected in $1.5 \mathrm{ml}$ Eppendorf tubes and further incubated in the lysis buffer for 10 minutes at $4^{\circ} \mathrm{C}$ on a spinning wheel. Lysates were sonicated and centrifuged for 10 minutes at $4^{\circ} \mathrm{C}$ at maximum speed and the supernatant was collected in new $1.5 \mathrm{ml}$ Eppendorf tubes. The protein content of each sample was measured using a Bradford assay (ROTI nano-quant) and $200 \mu \mathrm{g}$ of cleared lysates were put aside as total loading.

For pre-clearing, $2 \mathrm{mg}$ of protein were incubated for 6 minutes at $4^{\circ} \mathrm{C}$ on a spinning wheel with Protein $\mathrm{G}$ beads (Dynabeads, Invitrogen) to eliminate non-specific binding of proteins to beads. Pre-cleared lysates were incubated overnight with $2.5 \mu \mathrm{g}$ of antiAROS antibody (HPA042874, Sigma) at $4^{\circ} \mathrm{C}$ on a spinning wheel. The following day, $30 \mu \mathrm{l}$ of slurry Protein $\mathrm{G}$ beads were added to each sample and incubated at $4^{\circ} \mathrm{C}$ on a spinning wheel for 3 hours. Samples were washed three times in lysis buffer and resuspended in 1x SDS loading buffer. Samples were electrophoretically separated using a Bio-Rad 5-15 \% Criterion Precast Gel, transferred onto a nitrocellulose membrane and blotted for protein analyses. The following antibodies were used: antipan di/trimethyl-lysine (Abcam, ab23367), anti-AROS (Sigma, HPA042874), anti-Actin (Sigma, A5316), anti-H3K14me (Euromedex, H3-2B10), horseradish peroxidase (HRP)-conjugated secondary antibodies (DAKO). Immunoblots were revealed with a G:Box system (Syngene). 
Hela cells were transfected for 48 hours with Fugene reagent (Promega) and then processed for immunofluorescence studies. AROS cDNA cloned into the pCMV6 vector was purchased from Origene (RC207661). The romA gene was amplified as described. ${ }^{13}$ Immunofluorescence studies were performed on cells fixed in $4 \%$ paraformaldehyde (Electron Microscopy Sciences). The actin cytoskeleton was labeled using $1 \mathrm{\mu g} / \mathrm{ml}$ TRITC-conjugated phalloidin (Invitrogen). The anti-FLAG (Sigma, F1804) and anti-myc (Roche, 11667149001) mouse antibodies were used and detected by TRITC- or FITC-conjugated secondary antibodies (Invitrogen). To detect signal co-localization in co-transfected cells, we labeled primary antibodies with FITC and Cy3 LinKine Labeling kits (Abbkine). The fluorescent signals were analyzed with an SP8 confocal microscope equipped with a 63x magnification lens (Leica).

\section{Acknowledgments}

This work has been supported by the DFG (AJ, project JE252/7). Work in CB laboratory is financed by the Institut Pasteur, the Centre national de la recherche scientifique (CNRS), the Agency National de Recherche (ANR) grant $n^{\circ}$ ANR-10-LABEX-62-IBEID, the Infect-ERA project EUGENPATH (ANR-13-IFEC-0003-02) and by the Fondation pour la Recherche Médicale (FRM) grant N DEQ20120323697.

\section{References}

1. Fraser, D. W., Tsai, T. R., Orenstein, W., Parkin, W. E., Beecham, H. J., Sharrar, R. G., Harris, J., Mallison, G. F., Martin, S. M., McDade, J. E., Shepard, C. C. \& Brachman, P. S. (1977). Legionnaires' disease: description of an epidemic of pneumonia. N Engl J Med 297, 1189-97.

2. Berger, K. H. \& Isberg, R. R. (1993). Two distinct defects in intracellular growth complemented by a single genetic locus in Legionella pneumophila. Mol Microbiol 7, 7-19.

3. Marra, A., Blander, S. J., Horwitz, M. A. \& Shuman, H. A. (1992). Identification of a Legionella pneumophila locus required for intracellular multiplication in human macrophages. Proc Natl Acad Sci U S A 89, 9607-11.

4. Segal, G., Purcell, M. \& Shuman, H. A. (1998). Host cell killing and bacterial conjugation require overlapping sets of genes within a 22-kb region of the Legionella pneumophila genome. Proc Natl Acad Sci U S A 95, 1669-74.

5. Isaac, D. T. \& Isberg, R. (2014). Master manipulators: an update on Legionella pneumophila $\mathrm{lcm} /$ Dot translocated substrates and their host targets. Future Microbiol 9, 343-59.

6. Cazalet, C., Rusniok, C., Bruggemann, H., Zidane, N., Magnier, A., Ma, L., Tichit, M., Jarraud, S., Bouchier, C., Vandenesch, F., Kunst, F., Etienne, J., 
Glaser, P. \& Buchrieser, C. (2004). Evidence in the Legionella pneumophila genome for exploitation of host cell functions and high genome plasticity. Nat Genet 36, 1165-73.

7. Escoll, P., Mondino, S., Rolando, M. \& Buchrieser, C. (2016). Targeting of host organelles by pathogenic bacteria: a sophisticated subversion strategy. Nat Rev Microbiol 14, 5-19.

8. Rolando, M., Gomez-Valero, L. \& Buchrieser, C. (2015). Bacterial remodelling of the host epigenome: functional role and evolution of effectors methylating host histones. Cell Microbiol 17, 1098-107.

9. Margueron, R. \& Reinberg, D. (2010). Chromatin structure and the inheritance of epigenetic information. Nat Rev Genet 11, 285-96.

10. Bannister, A. J. \& Kouzarides, T. (2011). Regulation of chromatin by histone modifications. Cell Res 21, 381-95.

11. Allis, C. D. \& Jenuwein, T. (2016). The molecular hallmarks of epigenetic control. Nat Rev Genet 17, 487-500.

12. Bierne, H., Hamon, M. \& Cossart, P. (2012). Epigenetics and bacterial infections. Cold Spring Harb Perspect Med 2, a010272.

13. Rolando, M., Sanulli, S., Rusniok, C., Gomez-Valero, L., Bertholet, C., Sahr, T., Margueron, R. \& Buchrieser, C. (2013). Legionella pneumophila effector RomA uniquely modifies host chromatin to repress gene expression and promote intracellular bacterial replication. Cell Host Microbe 13, 395-405.

14. Son, J., Jo, C. H., Murugan, R. N., Bang, J. K., Hwang, K. Y. \& Lee, W. C. (2015). Crystal structure of Legionella pneumophila type IV secretion system effector LegAS4. Biochem Biophys Res Commun 465, 817-24.

15. Li, T., Lu, Q., Wang, G., Xu, H., Huang, H., Cai, T., Kan, B., Ge, J. \& Shao, F. (2013). SET-domain bacterial effectors target heterochromatin protein 1 to activate host rDNA transcription. EMBO Rep 14, 733-40.

16. Rolando, M. \& Buchrieser, C. (2014). Legionella pneumophila type IV effectors hijack the transcription and translation machinery of the host cell. Trends Cell Biol 24, 771-8.

17. Clarke, S. G. (2013). Protein methylation at the surface and buried deep: thinking outside the histone box. Trends Biochem Sci 38, 243-52.

18. Lanouette, S., Mongeon, V., Figeys, D. \& Couture, J. F. (2014). The functional diversity of protein lysine methylation. Mol Syst Biol 10, 724.

19. Zhang, X., Huang, Y. \& Shi, X. (2015). Emerging roles of lysine methylation on non-histone proteins. Cell Mol Life Sci 72, 4257-72.

20. Rathert, P., Dhayalan, A., Murakami, M., Zhang, X., Tamas, R., Jurkowska, R., Komatsu, Y., Shinkai, Y., Cheng, X. \& Jeltsch, A. (2008). Protein lysine methyltransferase G9a acts on non-histone targets. Nat Chem Bio/ 4, 344-6.

21. Dhayalan, A., Kudithipudi, S., Rathert, P. \& Jeltsch, A. (2011). Specificity analysis-based identification of new methylation targets of the SET7/9 protein lysine methyltransferase. Chem Biol 18, 111-20. 
22. Kudithipudi, S., Lungu, C., Rathert, P., Happel, N. \& Jeltsch, A. (2014). Substrate specificity analysis and novel substrates of the protein lysine methyltransferase NSD1. Chem Biol 21, 226-37.

23. Kudithipudi, S., Schuhmacher, M. K., Kebede, A. F. \& Jeltsch, A. (2017). The SUV39H1 Protein Lysine Methyltransferase Methylates Chromatin Proteins Involved in Heterochromatin Formation and VDJ Recombination. ACS Chem Biol 12, 958-968.

24. Kudithipudi, S., Kusevic, D., Weirich, S. \& Jeltsch, A. (2014). Specificity analysis of protein lysine methyltransferases using SPOT peptide arrays. $J$ Vis Exp, e52203.

25. Crooks, G. E., Hon, G., Chandonia, J. M. \& Brenner, S. E. (2004). WebLogo: a sequence logo generator. Genome Res 14, 1188-90.

26. Obenauer, J. C., Cantley, L. C. \& Yaffe, M. B. (2003). Scansite 2.0: Proteomewide prediction of cell signaling interactions using short sequence motifs. Nucleic Acids Res 31, 3635-41.

27. Kim, E. J., Kho, J. H., Kang, M. R. \& Um, S. J. (2007). Active regulator of SIRT1 cooperates with SIRT1 and facilitates suppression of p53 activity. Mol Cell 28, 277-90.

28. Kudithipudi, S. \& Jeltsch, A. (2016). Approaches and Guidelines for the Identification of Novel Substrates of Protein Lysine Methyltransferases. Cell Chem Biol.

29. Patel, D. J. \& Wang, Z. (2013). Readout of epigenetic modifications. Annu Rev Biochem 82, 81-118.

30. Fukuoka, M., Daitoku, H., Hatta, M., Matsuzaki, H., Umemura, S. \& Fukamizu, A. (2003). Negative regulation of forkhead transcription factor AFX (Foxo4) by CBP-induced acetylation. Int $\mathrm{J}$ Mol Med 12, 503-8.

31. van der Horst, A., Tertoolen, L. G., de Vries-Smits, L. M., Frye, R. A., Medema, R. H. \& Burgering, B. M. (2004). FOXO4 is acetylated upon peroxide stress and deacetylated by the longevity protein hSir2(SIRT1). J Biol Chem 279, 28873-9.

32. Knight, J. R., Willis, A. E. \& Milner, J. (2013). Active regulator of SIRT1 is required for ribosome biogenesis and function. Nucleic Acids Res 41, 4185-97.

33. George, R. A., Lin, K. \& Heringa, J. (2005). Scooby-domain: prediction of globular domains in protein sequence. Nucleic Acids Res 33, W160-3.

34. Jeltsch, A. \& Lanio, T. (2002). Site-directed mutagenesis by polymerase chain reaction. Methods $\mathrm{Mol} \mathrm{Biol}$ 182, 85-94.

35. Frank, R. (2002). The SPOT-synthesis technique. Synthetic peptide arrays on membrane supports--principles and applications. J Immunol Methods 267, 1326.

36. Feeley, J. C., Gibson, R. J., Gorman, G. W., Langford, N. C., Rasheed, J. K., Mackel, D. C. \& Baine, W. B. (1979). Charcoal-yeast extract agar: primary isolation medium for Legionella pneumophila. J Clin Microbiol 10, 437-41. 


\section{Tables}

Table 1: Novel non-histone RomA peptide substrates identified in Fig. 3A. ${ }^{\text {a) }}$

\begin{tabular}{|c|c|c|c|c|c|}
\hline Spot & Protein name & $\#$ & Pos & PepSeq & Pep-M \\
\hline 1 & H3 (7-21) & P68431 & 14 & ARKSTGGKAPRKQLA & +++ \\
\hline 3 & $\begin{array}{l}\text { Down syndrome cell } \\
\text { adhesion molecule- } \\
\text { like protein } 1\end{array}$ & Q8TD84 & 1287 & VTIEPAGKKAPAKIIS & + \\
\hline 7 & $\begin{array}{l}\text { Rho guanine } \\
\text { nucleotide exchange } \\
\text { factor } 17\end{array}$ & Q96PE2 & 821 & VDDRIAGK్APKKKSL & +++ \\
\hline 17 & Host cell factor 1 & P51610 & 511 & RPASQAGKAPVTVTS & + \\
\hline 19 & $\begin{array}{l}\text { E3 ubiquitin-protein } \\
\text { ligase UBR4 }\end{array}$ & Q5T4S7 & 4085 & RGIDGNGKAPSKSEL & + \\
\hline 27 & Zinc finger protein 703 & Q9H7S9 & 25 & SGSGGGGKRPPAVPAA & ++ \\
\hline 37 & $\begin{array}{l}\text { Zinc finger and BTB } \\
\text { domain-containing } \\
\text { protein } 47\end{array}$ & Q9UFB7 & 26 & EAGRRGGKKRPKPPPG & +++ \\
\hline 41 & $\begin{array}{l}\text { Zinc finger protein } \\
385 \mathrm{C}\end{array}$ & Q66K41 & 321 & HKDRLAGKTTPKPSSQ & ++ \\
\hline 43 & $\begin{array}{l}\text { DNA repair protein } \\
\text { complementing XP-C } \\
\text { cells }\end{array}$ & Q01831 & 332 & KSATAKGKKKPSKERL & + \\
\hline 45 & ATPase WRNIP1 & Q96S55 & 141 & PGRKGSGKRPAAAAA & + \\
\hline 53 & $\begin{array}{l}\text { Thymocyte selection- } \\
\text { associated high } \\
\text { mobility group box } \\
\text { protein TOX }\end{array}$ & 094900 & 245 & RPASDMGKKKPKTPKK & + \\
\hline 55 & $\begin{array}{l}\text { TOX high mobility } \\
\text { group box family } \\
\text { member } 3\end{array}$ & 015405 & 239 & RAAPDSGKKKPKTPKK & + \\
\hline 61 & Treacle protein & Q13428 & 155 & VANLLSGKKSPRKSAE & + \\
\hline 69 & Protein SON & P18583 & 2370 & AMKDLSG్HPVSALM & + \\
\hline 77 & $\begin{array}{l}\text { Retinoic acid-induced } \\
\text { protein } 1\end{array}$ & Q7Z5J4 & 1496 & DNSGGGGKKKPKMEEL & ++ \\
\hline 87 & $\begin{array}{l}\text { Unconventional } \\
\text { myosin-XVIIIlb }\end{array}$ & Q8IUG5 & 623 & PSVPSAGKKVPKGRRD & ++ \\
\hline 89 & Protein CBFA2T2 & O43439 & 234 & MEVHGNGKKRPSPERR & ++ \\
\hline 91 & $\begin{array}{l}\text { MOB kinase activator } \\
2\end{array}$ & Q70IA6 & 15 & SKAKPNGKKKPAAEER & ++ \\
\hline 95 & $\begin{array}{l}\text { Mediator of RNA } \\
\text { polymerase II } \\
\text { transcription subunit } \\
26\end{array}$ & 095402 & 220 & ENDKHSGKIIPVNAVR & +++ \\
\hline 97 & $\begin{array}{l}\text { Mediator of RNA } \\
\text { polymerase II } \\
\text { transcription subunit } 1\end{array}$ & Q15648 & 1293 & QHGSSKGKKSPSRNKK & ++ \\
\hline 99 & $\begin{array}{l}\text { Mediator of RNA } \\
\text { polymerase II } \\
\text { transcription subunit } \\
13\end{array}$ & Q9UHV7 & 366 & STSHHGGKIPRKLAN & + \\
\hline
\end{tabular}




\begin{tabular}{|c|c|c|c|c|c|}
\hline 103 & $\begin{array}{l}\text { Mastermind-like } \\
\text { domain-containing } \\
\text { protein } 1\end{array}$ & Q13495 & 34 & RKLQESGKKKPSWMEE & + \\
\hline 107 & Ceramide synthase 2 & Q96G23 & 93 & HFYLTSGKKQPKQVEV & ++ \\
\hline 109 & $\begin{array}{l}\text { Kinesin-like protein } \\
\text { KIFC1 }\end{array}$ & Q9BW19 & 129 & VPPMAGGKKKPSKRPA & + \\
\hline 111 & $\begin{array}{l}\text { Kinesin-like protein } \\
\text { KIF14 }\end{array}$ & Q15058 & 908 & PVEVQKGKKRPSGRDT & + \\
\hline 115 & $\begin{array}{l}\text { Interferon regulatory } \\
\text { factor } 2\end{array}$ & P14316 & 123 & ERPSKKGKKPKTEKE & ++ \\
\hline 139 & $\begin{array}{l}\text { Forkhead box protein } \\
04\end{array}$ & P98177 & 189 & PEGGKSGKKAPRRRAA & +++ \\
\hline 141 & $\begin{array}{l}\text { Forkhead box protein } \\
\text { O3 }\end{array}$ & O43524 & 245 & PDGGKSGKAPRRRAV & +++ \\
\hline 153 & $\begin{array}{l}\text { Death-inducer } \\
\text { obliterator } 1\end{array}$ & Q9BTC0 & 559 & PPGSAVGKQPAPRNL & + \\
\hline 155 & $\begin{array}{l}\text { Cleavage stimulation } \\
\text { factor subunit } 3\end{array}$ & Q12996 & 114 & YVRETKGKLPSYKEK & + \\
\hline 177 & $\begin{array}{l}\text { Ribosome biogenesis } \\
\text { protein BMS1 } \\
\text { homolog }\end{array}$ & Q14692 & 1187 & KTQAKAGKVVPKDRRR & + \\
\hline 179 & BCL-6 corepressor & Q6W2J9 & 392 & AARLSNGK్YPKAPEG & + \\
\hline 181 & $\begin{array}{l}\text { HMG box transcription } \\
\text { factor BBX }\end{array}$ & Q8WY36 & 19 & AEGEGVGKKRPKRKCL & +++ \\
\hline 183 & $\begin{array}{l}\text { Protein atonal } \\
\text { homolog } 8\end{array}$ & Q96SQ7 & 31 & KKLKRKGKEEPARRAN & + \\
\hline 185 & $\begin{array}{l}\text { Active regulator of } \\
\text { SIRT1 }\end{array}$ & Q86WX3 & 54 & LRNSAKGK్VPKSALD & ++ \\
\hline
\end{tabular}

a) Spot - spot number in Fig. 3A, \# - UniProtKB entry number, Pos - position of the target lysine, PepSeq - peptide sequence with target lysine underlined, Pep-M indicates the methylation intensity. 
Table 2: Non-histone RomA protein substrates. ${ }^{\text {a) }}$

\begin{tabular}{|c|c|c|c|c|c|c|}
\hline Protein name & Abb & \# & Pos & Domain & PepSeq & Prot-M \\
\hline $\begin{array}{l}\text { Active } \\
\text { regulator of } \\
\text { SIRT1 }\end{array}$ & AROS & Q86WX3 & 54 & full length & $\begin{array}{l}\text { LRNSAKGK } \\
\text { VPKSALD }\end{array}$ & +++ \\
\hline $\begin{array}{l}\text { Kinesin-like } \\
\text { protein KIFC1 }\end{array}$ & KIFC1 & Q9BW19 & 129 & $1-316$ & $\begin{array}{l}\text { VPPMAGGK } \\
\text { KPSKRPA }\end{array}$ & +++ \\
\hline $\begin{array}{l}\text { Forkhead box } \\
\text { protein } 04\end{array}$ & FOXO4 & P98177 & 189 & $2-221$ & $\begin{array}{l}\text { PEGGKSGK } \\
\text { APRRRAA }\end{array}$ & +++ \\
\hline $\begin{array}{l}\text { Retinoic acid- } \\
\text { induced } \\
\text { protein } 1\end{array}$ & RAl1 & Q7Z5J4 & 1496 & $1395-1586$ & $\begin{array}{l}\text { DNSGGGGK } \\
\text { KPKMEEL }\end{array}$ & +++ \\
\hline $\begin{array}{l}\text { Mediator of } \\
\text { RNA } \\
\text { polymerase II } \\
\text { transcription } \\
\text { subunit } 13\end{array}$ & MED13 & Q9UHV7 & 366 & $212-474$ & $\begin{array}{l}\text { STSHHGGKI } \\
\text { PRKLAN }\end{array}$ & ++ \\
\hline $\begin{array}{l}\text { HMG box } \\
\text { transcription } \\
\text { factor BBX }\end{array}$ & BBX & Q8WY36 & 19 & $9-152$ & $\begin{array}{l}\text { AEGEGVGK } \\
\text { RPKRKCL }\end{array}$ & + \\
\hline $\begin{array}{l}\text { Protein } \\
\text { CBFA2T2 }\end{array}$ & CBFA2T2 & 043439 & 234 & $114-325$ & $\begin{array}{l}\text { MEVHGNGKK } \\
\text { RPSPERR }\end{array}$ & + \\
\hline Treacle protein & TCOF1 & Q13428 & 155 & $82-215$ & $\begin{array}{l}\text { VANLLSGKS } \\
\text { PRKSAE }\end{array}$ & - \\
\hline $\begin{array}{l}\text { Kinesin-like } \\
\text { protein KIF14 }\end{array}$ & KIF14 & Q15058 & 908 & $809-1076$ & $\begin{array}{l}\text { PVEVQKGK } \\
\text { RPSGRDT }\end{array}$ & - \\
\hline
\end{tabular}

a) Abb - abbreviation, \# - UniProtKB entry number, Pos - position of the target lysine, Domain - boundaries of the cloned domains in amino acids, PepSeq - peptide sequence with target lysine underlined, Prot-M - relative level of protein methylation. 


\section{Figures}
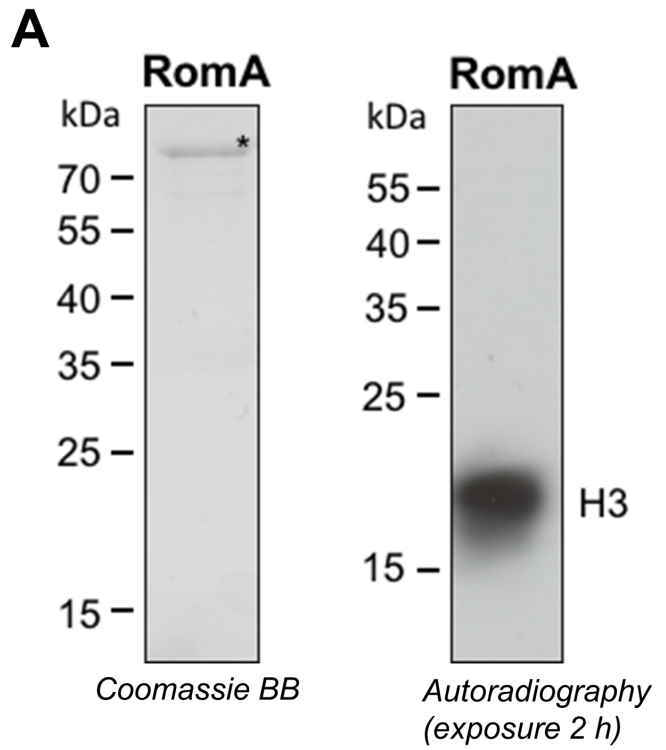

\begin{tabular}{|c|c|c|}
\hline Spot No. & Protein name & Sequence \\
\hline 1 & H3 (1-15) & ARTKQTARKSTGGKA \\
\hline 2 & H3K4A & ARTAQTARKSTGGKA \\
\hline 3 & H3K9A & ARTKQTARASTGGKA \\
\hline 4 & H3K14A (1-15) & ARTKQTARKSTGGAA \\
\hline 5 & H3K14 (7-21) & ARKSTGGKAPRKQLA \\
\hline 6 & H3K14A & ARKSTGGAAPRKQLA \\
\hline 7 & H3K27 (19-33) & QLATKAARKSAPATG \\
\hline 8 & H3K27A & QLATKAARASAPATG \\
\hline 9 & H3K36 (29-43) & APATGGVKKPHRYRP \\
\hline 10 & H3K36A & APATGGVAKPHRYRP \\
\hline 11 & H3K79 (72-86) & REIAQDFKTDLRFQS \\
\hline 12 & H3К79A & REIAQDFATDLRFQS \\
\hline 13 & H4 (13-27) & GGAKRHRKVLRDNIQ \\
\hline 14 & $\mathrm{H} 4 \mathrm{~K} 20 \mathrm{~A}$ & GGAKRHRAVLRDNIQ \\
\hline
\end{tabular}

Fig. 1: Confirmation of the RomA enzyme activity and target lysine scan. A) The left panel shows the purified GST-tagged RomA protein after loading on an SDS-PAGE and staining with Coomassie BB. The asterisk indicates the band of RomA. The right panel shows the activity validation of RomA. A methylation reaction was performed using radioactively labeled AdoMet, RomA and recombinant $\mathrm{H} 3$ as substrate. The methylation sample was separated on SDS-PAGE and the signal was detected by autoradiography. B) Target lysine scan of RomA at peptide level. Fifteen amino acid long peptides were synthesized on a membrane using human $\mathrm{H} 3$ or $\mathrm{H} 4$ as sequence template. Afterwards, the peptide array was incubated with RomA in buffer containing radioactively labeled AdoMet, which was followed by the visualization of the transferred radioactive methyl groups by autoradiography. The numbers above the film indicate the different spots, the corresponding sequences are given in the table below the image. Note the specific and strong methylation of spot 5 . 

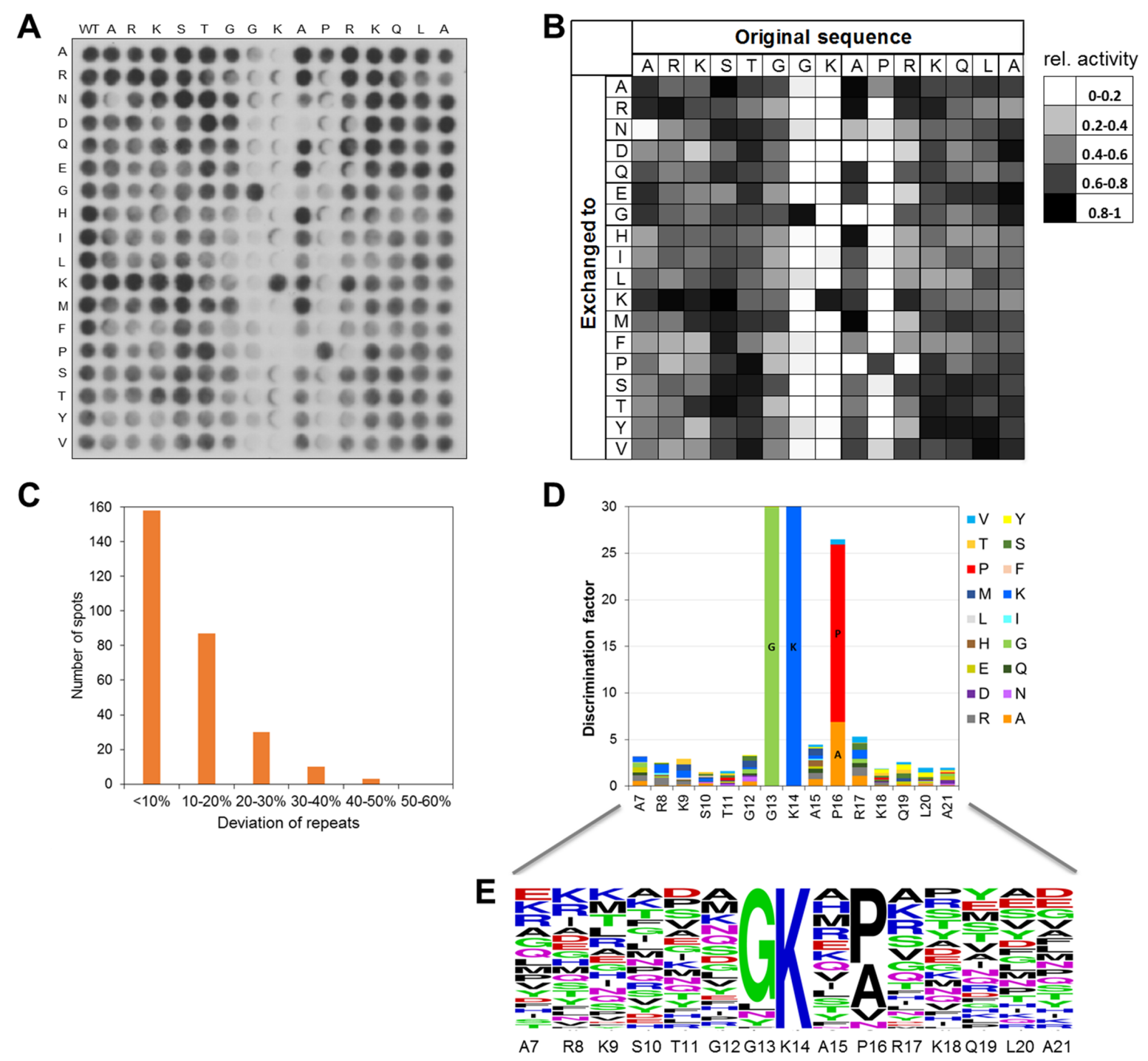

Fig. 2: Analysis of the substrate specificity of RomA. A) For the substrate specificity analysis of RomA, arrays of fifteen amino acid long peptides were synthesized using H3 (7-21) as template sequence (WT column). All other peptides contain single amino acid exchanges, in which one residue (shown on the horizontal axis) is exchanged against all 18 other residues (shown in the vertical axis). The membrane was incubated with RomA and radioactively labeled AdoMet, which was followed by the visualization of the methylation signals by autoradiography (represented as black dots). B) Quantification of two independent specificity arrays of RomA. The signals of the individual experiments were normalized and averaged and the signal intensity is shown as a greyscale. C) Standard deviations of the methylation signals at each spot in the duplicated substrate specificity peptide array experiments. D) Discrimination factors of the substrate specificity of RomA showing the preference for particular amino acids at different positions of $\left.\mathrm{H} 3(7-21) \cdot{ }^{24} \mathrm{E}\right)$ Sequence logo of the specificity profile of RomA prepared using WebLogo (http://weblogo.berkeley.edu/). ${ }^{25}$ 
A

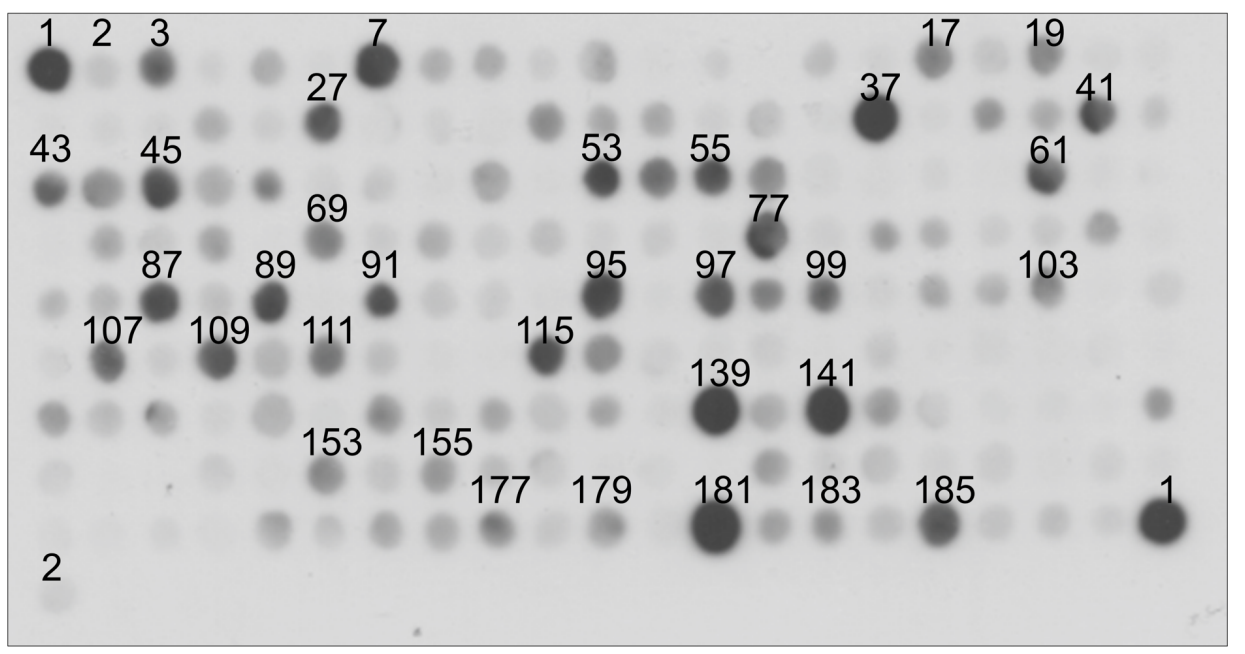

B

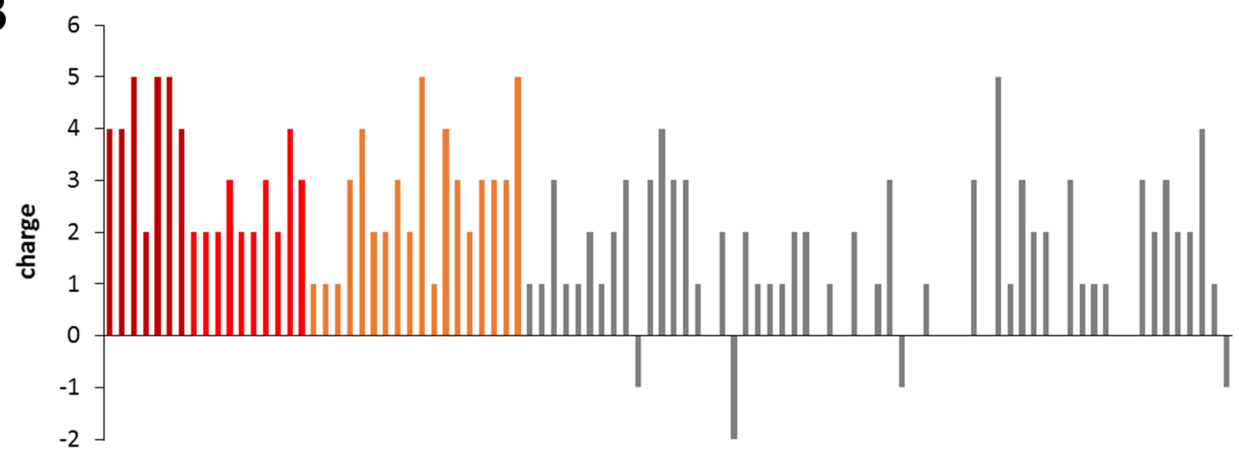

Fig. 3: Non-histone target peptide array. A) The identified candidate RomA substrates were synthesized as fifteen amino acid long peptides on a membrane and afterwards the membrane was incubated with RomA and radioactively labeled AdoMet. The methylation signals were detected by autoradiography. The two spots labeled with 1 represent the positive control H3K14 (7-21) and the two spots labeled with 2 represent the corresponding negative controls in which the target lysine K14 is mutated to alanine (H3K14A). The annotated 34 spots are listed in Table 1. They show a strong to medium methylation signal that disappeared in the target $\mathrm{K}$ to $\mathrm{A}$ mutant peptide controls and were further analyzed at protein level in vitro. About 15 additional peptides showed weaker methylation signals. B) Analysis of the charge of methylated and unmethylated peptides. Peptides were ranked by methylation activity (left to right) and the charge of the region of the target site \pm 5 residues was calculated and plotted. Note the enrichment of positively charged peptides in the group of methylated substrates. The p-value of charge distribution between methylated and unmethylated peptides was $7.67 \times 10^{-7}$ calculated in Excel using a two-sided T-Test with unequal variance. All spotted non-histone peptide sequences are provided in Suppl. Table 1 sorted by methylation levels as plotted in panel B. 

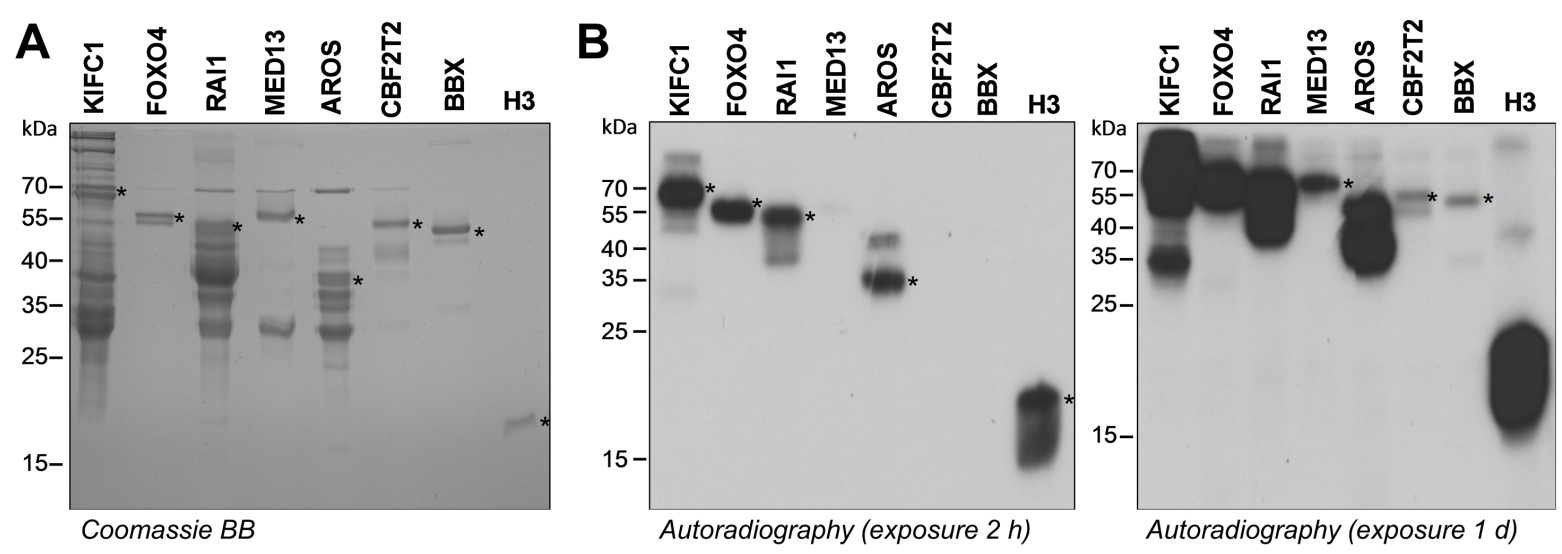

Fig. 4: Protein analysis and methylation of non-histone proteins and protein domains. A) The candidate substrate proteins were purified by affinity chromatography using glutathione sepharose beads. The SDS-PAGE shows comparable loading of the seven purified proteins and recombinant $\mathrm{H} 3$, which was used as positive control in the methylation reaction. The target protein band is marked by asterisks. B) The nonhistone target proteins were incubated with radioactively labeled AdoMet and RomA. The methylated proteins were separated by SDS-PAGE and the transfer of radioactive methyl groups was visualized by autoradiography. The asterisks indicated the size of the non-histone target proteins. Two films are shown with different exposure times to visualize the weaker methylated targets as well. 

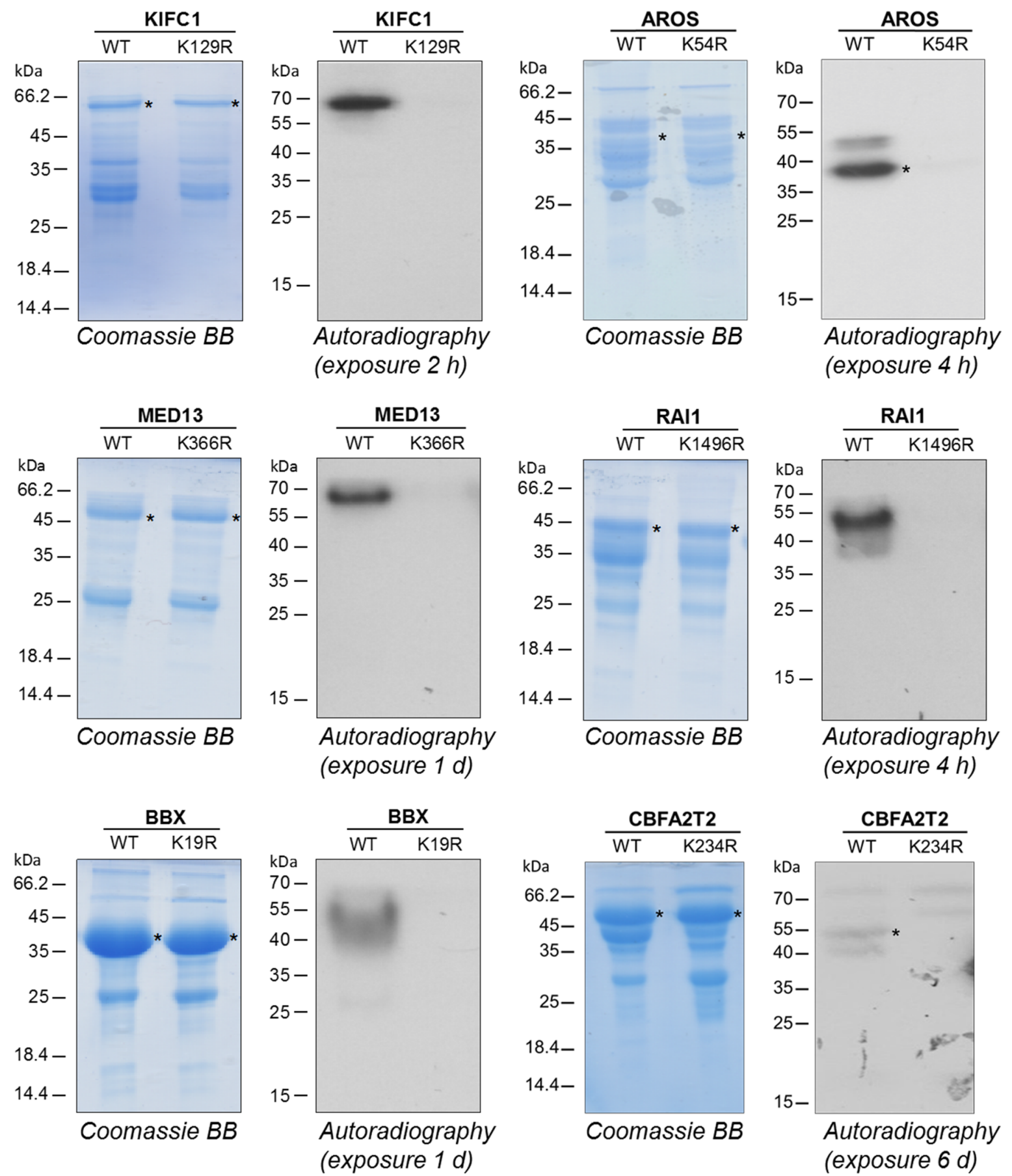

Fig. 5: Validation of target lysine methylation in the novel non-histone protein and protein domain substrates KIFC1, AROS, MED13, RAI1, BBX and CBFA2T2. The GST-tagged wild type and target lysine mutant proteins were analyzed by SDS-PAGE and visualized by Coomassie BB staining, the target protein band is indicated by asterisks. The proteins were incubated with radioactively labeled AdoMet and RomA. The methylated samples were separated by SDS-PAGE and the transfer of radioactive methyl groups was detected by autoradiography. For FOXO4 refer to Fig. 6 . 
A

K174: KVHNEATG SSWWMLNP

K186: WMLNPEGGKSGKAPRRR

K189: NPEGGKSGKAPRRRAAS

K210: SKLLRGRSKAPKKKPSV

D

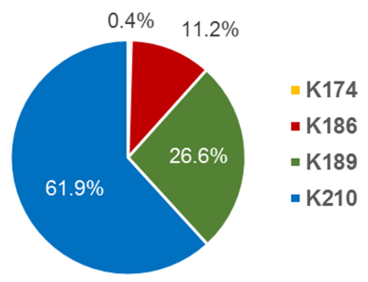

B

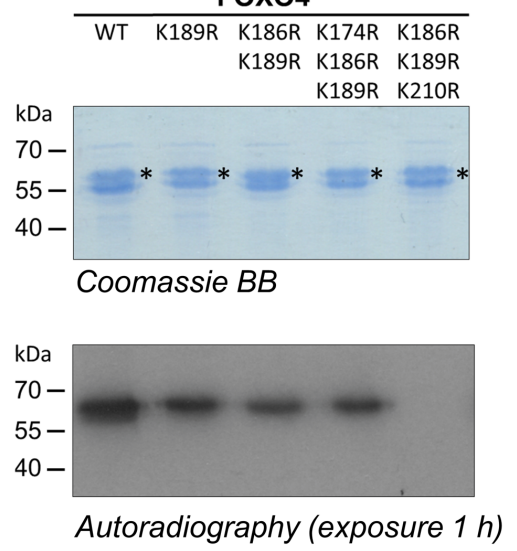

C

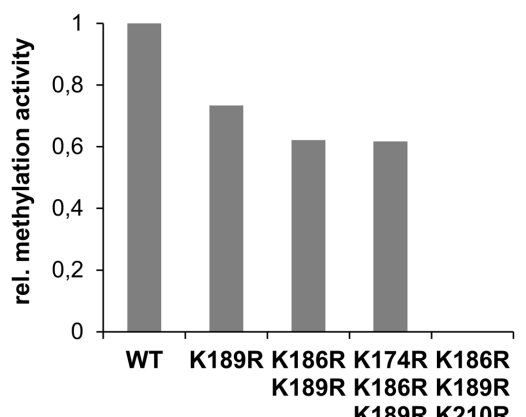

Fig. 6: Analysis of target lysine methylation in FOXO4. A) Sequences of four potential target $\mathrm{K}$ residues in FOXO4 (showing in yellow, red, green and blue). The \pm 5 region of the potential target $\mathrm{K}$ is shaded in grey. Residues matching to the preferences of RomA are underlined. B) The GST-tagged wild type and target lysine mutant proteins were analyzed by SDS-PAGE and visualized by Coomassie BB staining, the target protein band is indicated by asterisks. The proteins were incubated with radioactively labeled AdoMet and RomA. The methylated samples were separated by SDS-PAGE and the transfer of radioactive methyl groups was detected by autoradiography. C) Band intensities were analyzed in the autoradiographic images and quantified. Repeated experiments revealed an error range of the relative methylation activities of $\pm 9 \%$. D) Relative contribution of all four target sites to the overall methylation of FOXO4. 
A

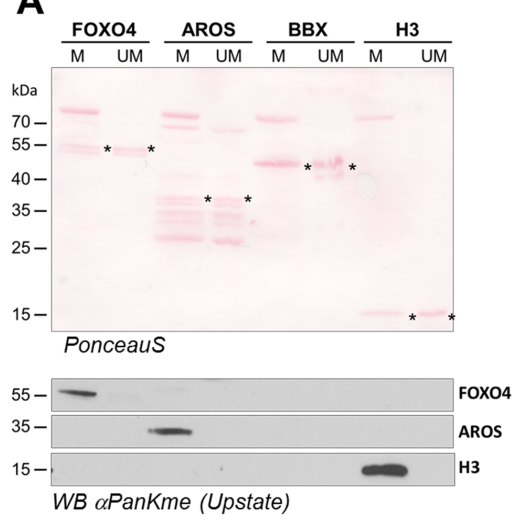

B

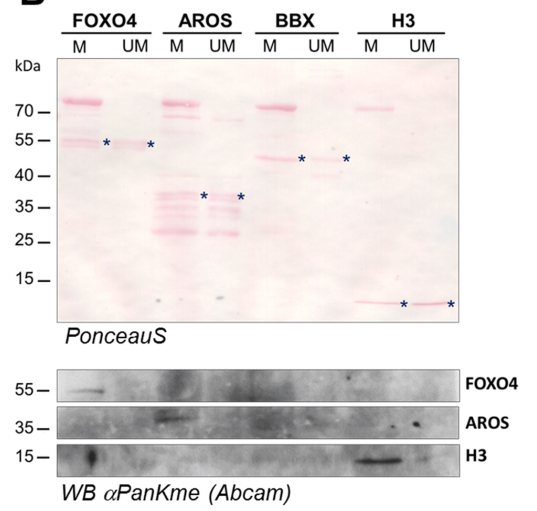

C

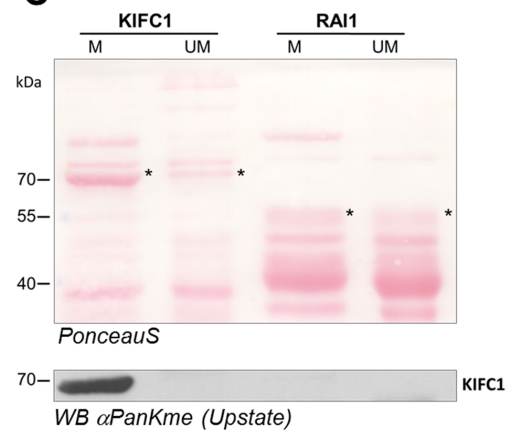

Fig. 7: Non-histone protein methylation and anti-pan di/trimethyl-lysine antibody validation. The FOXO4, AROS, BBX, KIFC1, RAI1 and recombinant $\mathrm{H} 3$ proteins were methylated by RomA using unlabeled AdoMet (M). A corresponding unmethylated sample that was not incubated with RomA was included as negative control (UM). The samples were separated by SDS-PAGE followed by the transfer of the proteins onto a nitrocellulose membrane. The PonceauS images are shown as loading control. The asterisks indicate the GST-tagged non-histone protein size or the size of recombinant $\mathrm{H} 3$. A) Detection of the methylation of FOXO4, AROS and recombinant $\mathrm{H} 3$ with the anti-pan di/trimethyl-lysine antibody from Upstate. B) Methylation of the same substrates as shown in panel A but detected with anti-pan di/trimethyl-lysine antibody from Abcam. C) Detection of KIFC1 methylation with the anti-pan di/trimethyl-lysine antibody from Upstate. 

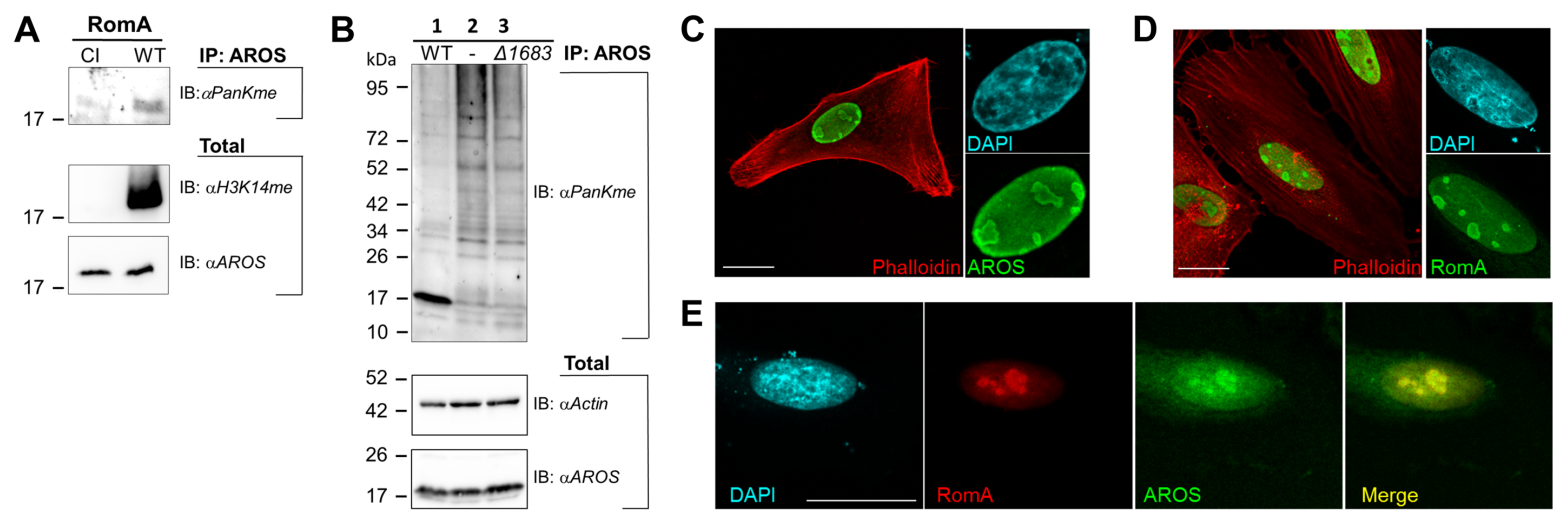

Fig. 8: In vivo methylation of AROS by RomA. A) Immunoprecipitation (IP) of AROS from HEK293T cells stably expressing wild type RomA (WT) or its catalytic inactive mutant $(\mathrm{Cl})$. The immunoblot with anti-pan di/trimethyl-lysine antibody (IB: $\alpha \mathrm{PanKMe})$ shows AROS methylation depending on RomA enzymatic activity. RomA activity was verified using an $\mathrm{H} 3 \mathrm{~K} 14 \mathrm{me}$ antibody in total lysates. Endogenous expression of AROS is shown as loading control. B) Immunoprecipitation (IP) of AROS from HEK293T cells using anti-AROS antibodies. Lane 1: IP after eight hours of infection with L. pneumophila Paris wild type; Lane 2: IP from uninfected cells; Lane 3: IP after eight hours of infection with $L$. pneumophila RomA mutant $(\Delta / p p 1683)$. The immunoblot with anti-pan di/trimethyl-lysine antibody (IB: $\alpha$ PanKMe) shows the AROS methylation in L. pneumophila infected cells in a RomA dependent-manner. Immunoblots on total lysates $(20 \mu \mathrm{g})$ show endogenous expression of AROS and Actin as loading controls. C-E) Immunofluorescence analyses of Hela cells showing co-localization of cotransfected AROS and RomA. Expression plasmids encoding a FLAG-tagged form of AROS (C) and a myc-tagged form of RomA (D) were used. Both proteins (green) show a nucleolar localization. The nucleus was stained with DAPI (cyan) and actin with TRITC-Phalloidin (Red). E) Hela cells were co-transfected with both FLAG-AROS and myc-RomA expression plasmids and subcellular localization was studied by using antiFLAG-FITC and anti-myc-Cy3 antibodies. The merge is displayed in yellow, nucleus in cyan (DAPI). Scale bars $10 \mu \mathrm{m}$. 